Orlando Ricardo Hung MD FRCPC,

Colin Bands MB ChB FRCPC,

Geoffrey Laney MB ChB FANZCA, David Drover MD,

Sarah Stevens MD FRCPC, Michael MacSween MD FRCPC*

\title{
Drug allergies in the surgical population
}

but most of the other drug classes, such as opioids (83\%),

Many patients claim to have drug allergies. However, the signs and symptoms of "allergic reactions" are seldom documented and the drug allergies are rarely properly assessed. The goal of this study was to determine the incidence of claimed "drug allergies" in a surgical population. After obtaining institutional approval, the study was carried out at five hospitals affiliated with Dalhousie University. Patients were interviewed by the investigators during the preoperative anaesthetic evaluation over six months and all signs and symptoms of drug reactions were recorded. The validity of the claimed allergy was based on the history. The allergies were assigned to one of three groups: (1) High probability of an allergic reaction: one or more of the signs and symptoms typical of an immunological reaction, with or without a family history, or a history of atopy; (ii) Low probability of an allergic reaction: signs and symptoms of the reaction were predictable reactions or side effects of the drug, without the occurrence of reactions mentioned above; or (iii) Unknown status. no information concerning the reaction of history was available. Of 1818 adult and paediatric patients (914 female 904 male) interviewed, 511 (28.1\%) claimed to have one or more drug allergies (a total of 671 allergies). More women than men claimed to have drug allergies $160.3 \%$ vs $39.7 \%$ ) and there was a positive correlation between age, number of medications and reported drug allergies. Antibiotics (50\%), opioids (27\%), non-steroidal anti-inflammatory agents (10\%), and sedatives (5\%) accounted for $92 \%$ of all claimed drug allergies. Overall, $50 \%$ of claimed allergies had a high probability of true allergic reactions. The majority of antibiotics (75\%) were associated with a high probability for true allergic reactions,

\section{Key words}

ALLERGY;

COMPLICATIONS: allergy;

EDUCATION.

From the Departments of Anaesthesia, Medicine* and Pharmacology, Dalhousie University, Halifax, Nova Scotia, Canada

Presented, in part, at the Canadian Anaesthetists' Society

Meeting in Toronto, Ontario, June, 1992.

Address correspondence to: Dr. Orlando R. Hung,

Department of Anaesthesia, Victoria General Hospital,

Halifax, Nova Scotia, Canada, B3H 2 Y9.

Accepted for publication 23rd July, 1994.
NSAIDs (64\%) and sedatives (67\%), were associated with a low probability for true allergic reactions. Our findings suggest a serious problem in the "labelling" of our patients as hoving drug allergies. Patients and health care personnel should be educated in the differentiation between predictable adverse drug reactions and true allergic drug reactions.

Plusieurs patients se disent victimes d'allergies. Toutefois, les signes et symptômes d'allergies médicamenteuses sont rarement documentés. Cette étude vise à déterminer lincidence des allergies médicamenteuses dans une population chirurgicale. Après approbation des organismes compétents, l'étude est menée dans cinq hôpitaux affiliés à l'université Dalhousie. Les patients sont interrogés par les investigateurs lors de l'évaluation préopératoire pendant une période de six mois. Les signes et symptômes des allergies médicamenteuses sont notés. La validité des allergies présumées est basée sur l'anamnèse. Les allergies sont classifiées de la façon survante en trois groupes. i) haute probabilité d'une réaction allergique: un ou plusieurs signes et symptômes d'une réaction immunologique, avec ou sans histoire familiale, ou avec une histoire d'atopie; ii) faible probabilité d'une réaction allergique: les signes et symptômes de la réaction étaient des manifestations prévisibles ou des effets secondaires de la drogue, sans les réaction décrites plus haut; iii) situation inconnue: aucune connaissance de la nature de la réaction ou de l'anamnèse. Mille huit cents adultes et enfants (914 femmes/904 hommes) ont été interrogés dont 511 (28,1\%) disaient avoir éprouvé une ou plusieurs réactions médicamenteuses (total: 671 allergies). Plus de femmes se sont dites sujettes aux allergies médicamenteuses (60,3\% vs 39,7\%). La corrélation avec des allergies déclarées est positive pour l'âge et le nombre de médicaments. Les antibiotiques (50\%), les morphiniques (27\%), les anti-inflammatoires non-stéroiddiens (10\%) et les sédatifs (5\%) représentent $92 \%$ de toutes les allergies déclarées. Au total, $50 \%$ des allergies déclarées présentent une probabilité élevée de vraies réactions médicamenteuses. La majorité des antibiotiques (75\%) est associẻe à une probabilité élevée de réactions allergiques vraies. D'autre part, la plupart des autres drogues, comme les morphiniques (83\%), les AINS (64\%) et les sédatifs $(67 \%)$ présentent un faible risque de réactions allergiques vraies. Nos résultats suggèrent une faille sérieuse dans nos méthodes d'identification des patients à risque de réaction allergique. Les patients, comme le personnel médical, devraient être mieux renseigné afin de pouvoir distinguer les réactions médicamenteuses indésirables des réactions allergiques vraies. 
At least 75 million adults in the United States regularly take two or more drugs. ${ }^{1}$ Both surgical and medical patients have been reported to take an average of nine to ten different drugs during their stay in hospital. The frequency of adverse drug reactions per course of therapy is high, ranging from 0.3 to $30 \%$ per treatment. ${ }^{1-4} \mathrm{Ad}-$ verse drug reactions (ADR) can be divided into: (i) predictable reactions as a result of the pharmacological properties of the drug which include side effects, toxic reactions and drug interactions; (ii) idiosyncratic reactions where the cause is unknown; (iii) immunological or immunological-like reactions when the drug or its by products interact with the immune system. ${ }^{4}$ Even though allergic or immunological drug reactions account for only 6-10\% of ADR, this group of reactions is frequently associated with catastrophic outcomes. ${ }^{3}$ Since prevention and detection are two of the most important components in the management of adverse drug reactions and allergies, anaesthetists must carry out a thorough preoperative evaluation of the patients' history of allergic drug reactions to minimize severe reactions.

Many patients claim to have drug allergies, but the signs and symptoms of "allergic reactions" are seldom documented by health care personnel including physicians. This results in erroneous labelling of patients as being allergic to some drugs, when many reactions represent predictable adverse side effects. Such incorrect labelling frequently denies patients medications which may be beneficial and alternative medications may be more dangerous, less effective and more costly.

There are considerable legal implications for physicians who disregard invalid purported drug allergies, and elect to use the drugs in question. Between 1977 and 1988, the Medical Inter-Insurance Exchange of New Jersey paid $>\$ 30 \mathrm{~m}$. in indemnity for medical malpractice suits arising from medication errors. ${ }^{5}$ The predominant category in which the health care providers incur liability involved a disregard of patient allergies to specific drugs such as acetylsalicylic acid, penicillin and its derivatives.

A few previous studies have examined the incidence of "true" drug allergy. ${ }^{6-13}$ However, they were mostly retrospective chart reviews of small numbers of patients. The goal of our study was to determine the incidence of claimed "drug allergies" in a surgical population.

\section{Methods}

After obtaining institutional approval, the study was carried out at several hospitals affiliated with Dalhousie University (Victoria General Hospital (VGH), Izaak Walton Killam Hospital for Children (IWK), Grace Maternity Hospital (GMH), Camp Hill Medical Centre (CHM) and Saint John Regional Hospital (SJRH). All patients who were seen by the investigators during their preoperative anaesthetic assessment in a six month period were included in the study. Most of the investigators were residents and fellows during the study period. Since they were exposed randomly to different rotations in different hospitals, the selection bias of the patient population should be minimal. We obtained allergy histories of paediatric patients from their parents. Patients who were unable to provide a history of drug allergies (e.g., during mechanical pulmonary ventilation) were excluded from the study. For the purpose of this study, allergies other than drug allergies were excluded. When the medication in question consisted of two or more major drugs, i.e., Tylenol \#3 (acetaminophen and codeine) and Frosst 292 (acetylsalicylic acid and codeine), all the components were considered as drug allergies. When patients claimed a drug allergy, a detailed history of the signs and symptoms of the "allergic reactions," family history of drug allergies, and history of atopy were taken. Documentation of the event and ensuing investigations were reviewed, and assessment was made of the validity of the claimed allergy.

Claimed drug allergies were assigned to one of three groups based on history and documentation of the claimed "allergic reactions":

(i) High Probability of an allergic or immunological drug reaction. This was considered if the patient manifested one or more of the following signs and symptoms typical of an immunological reaction, with or without a family history, or a history of atopy: (a) cutaneous manifestations such as swelling, rash, hives, blisters or severe itching; (b) respiratory compromise such as shortness of breath, wheeze or difficulty in breathing; (c) considerable decrease in blood pressure, or cardiovascular collapse.

(ii) Low probability. This was considered if the signs and symptoms of the reaction were predictable reactions or side effects of the drug, without the occurrence of reactions mentioned above. These included; (a) gastrointestinal disturbances (nausea, vomiting, epigastric distress, diarrhoea, constipation, colitis, etc.); (b) central nervous system disturbances (headache, dizziness, drowsiness, hallucination, nightmare, confusion, agitation, dysphoria, etc.); (c) non-specific symptoms (muscle cramps, irritability, anxiousness, shakiness, feeling high, emotional, excitation, sweatiness, stiffness, increase breast milk, addiction, etc.); (d) idiosyncratic reactions.

(iii) Unknown. The patient had no information concerning the reaction or was unable to provide a history.

The data were analyzed using regression analysis and Chi-squares analysis-of-contingency table (Systat ${ }^{\circledR}$, Systat Inc., Evanston, IL, USA) where appropriate. A $P$ value $<0.05$ was considered significant. 
TABLE I Demographic data

\begin{tabular}{|c|c|c|c|c|c|c|c|}
\hline $\begin{array}{l}\text { Age group } \\
(y r)\end{array}$ & $n$ & Women & Men & $\begin{array}{l}\% \text { receiving } \\
\text { medications }\end{array}$ & $\begin{array}{l}\text { Awerage number of } \\
\text { medications }\end{array}$ & $\begin{array}{l}\text { Patients with claimed drug } \\
\text { allergies (women/men) }\end{array}$ & $\begin{array}{l}\text { \% patients with claimed } \\
\text { drug allergies }\end{array}$ \\
\hline$<20$ & 133 & 64 & 68 & 21.2 & 0.37 & $15(7 / 8)$ & 11.3 \\
\hline $20-29$ & 274 & 146 & 128 & 25.7 & 0.45 & $50(31 / 19)$ & 18.2 \\
\hline $30-39$ & 302 & 171 & 131 & 35.7 & 0.66 & $71(49 / 22)$ & 23.5 \\
\hline $40-49$ & 258 & 143 & 115 & 49.2 & 1.18 & $81(59 / 22)$ & 31.4 \\
\hline $50-59$ & 233 & 99 & 134 & 67.9 & 1.89 & $68(37 / 31)$ & 29.2 \\
\hline $60-69$ & 264 & 129 & 135 & 76.9 & 2.59 & $96(51 / 45)$ & 36.4 \\
\hline$>70$ & 355 & $\underline{162}$ & $\underline{193}$ & $\underline{85.2}$ & $\underline{3.11}$ & $130(74 / 56)$ & $\underline{36.6}$ \\
\hline Total & $\overline{1818}$ & $\overline{914}$ & $\overline{904}$ & $\overline{54.9}$ & $\overline{1.6}$ & $511(308 / 203)$ & $\overline{28.1}$ \\
\hline
\end{tabular}

\section{Results}

A total of 1818 patients ranging from one to $85 \mathrm{yr}$ were interviewed during the period. Demographic data of the patients are shown in Table I. Of these, 511 (28.1\%) patients claimed one or more drug allergies, with a total of 671 drug allergies. The majority $(87 \%)$ of the studied patients were interviewed at the VGH and only $13 \%$ were interviewed at the remaining four hospitals (73 at SJRH, 39 at CHM, 70 at the IWK and 46 at the GMH). However, the incidence of claimed drug allergies was comparable among the three general hospitals $(28.8 \%$ at VGH, $27.7 \%$ at SJRH, and $28.2 \%$ at CHM). The incidence of claimed drug allergies at the maternity (GMH) and the children's hospital (IWK) were $37.0 \%$ and $7.1 \%$ respectively.

There was a positive correlation between the age of the patients and the number of claimed drug allergies ( $\mathrm{r}=0.734, P<0.005$, Figure 1). In other words, there were significantly more elderly patients claimed to have drug allergies than younger patients. However, more than $80 \%$ of the patients $>70 \mathrm{yr}$ took one or more medications compared with $25 \%$ or less in patients $<20$ yr (Table I). In addition, the average number of medications taken by elderly patients was considerably higher than that by young patients. Even though there was no sex difference in the use of medications ( $55.4 \%$ women vs $54.0 \%$ men), more women claimed to have drug allergies than men in all age groups $(P<0.001)$. Women had a higher percentage of low probability reactions than men $(49 \%$ versus $37 \%$ ). However, more men had unknown reactions than women ( $11 \%$ versus $3 \%$ ). Antibiotics (50\%), opioids (27\%), non-steroidal anti-inflammatory agents (10\%), and sedatives (5\%) together accounted for $92 \%$ of all claimed drug allergies (Figure 2). More patients were concurrently taking one or more medications reported to have drug allergies than patients taking no medications $(P<0.001)$. In addition; there was a correlation between the percentage of patients who claimed to have drug allergies and the number of medications taken by the patients $(r=$ $0.946, P<0.005$, Figure 3). In other words, more patients

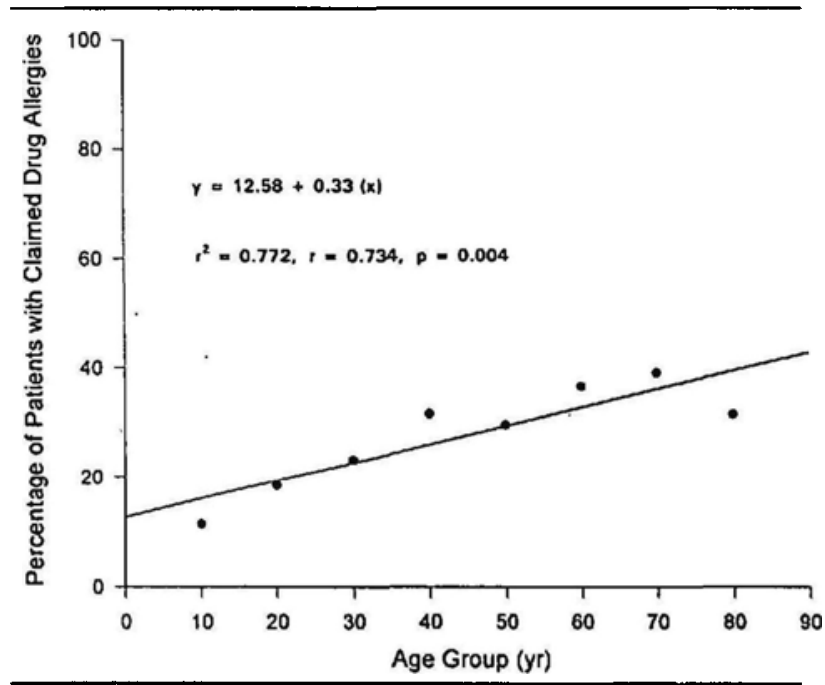

FIGURE 1 The relationship between age groups and percentage of patients claimed to have drug allergies.

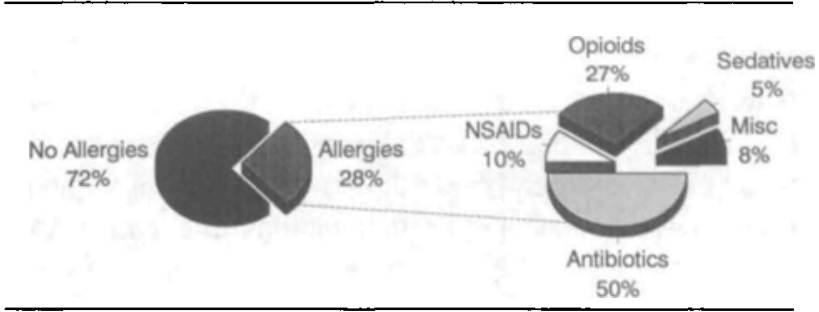

FIGURE 2 Percentages of claimed allergies of major drug groups in the studied surgical population.

using multiple medications claimed to have drug allergies than patients receiving no medications.

Overall, $50 \%$ of claimed drug allergies had a high probability of a true allergic reaction. The majority of claimed antibiotic allergies (75\%) were associated with a high probability of allergic reactions (Figure 4). Penicillin was the most commonly claimed drug allergy in the antibiotic group with $82 \%$ falling in the high probability group for allergic reaction (Table II). Sulphur 
TABLE II Validity of the claimed antibiotic allergies

\begin{tabular}{lccccc}
\hline Antibiotics & $\begin{array}{c}\text { High } \\
\text { prob }\end{array}$ & $\begin{array}{c}\text { Low } \\
\text { prob }\end{array}$ & Unknown & Total & $\begin{array}{l}\text { Percentage of claimed } \\
\text { antibiotic allergies }\end{array}$ \\
\hline Penicillins & 169 & 22 & 16 & 207 & 58.1 \\
Sulphur & 58 & 23 & 9 & 90 & 25.3 \\
Trimethoprim & 13 & 3 & 3 & 19 & 5.3 \\
Erythromycins & 8 & 3 & 0 & 11 & 3.1 \\
Tetracyclines & 8 & 2 & 1 & 11 & 3.1 \\
Cephalosporins & 6 & 2 & 0 & 8 & 2.2 \\
Others & 5 & 4 & $\frac{1}{30}$ & $\frac{10}{356}$ & $\frac{2.4}{100}$ \\
Total & 267 & 59 & 30 & 35 & \\
Percentage & 75 & 16.6 & 8.4 & 100 & \\
\hline
\end{tabular}

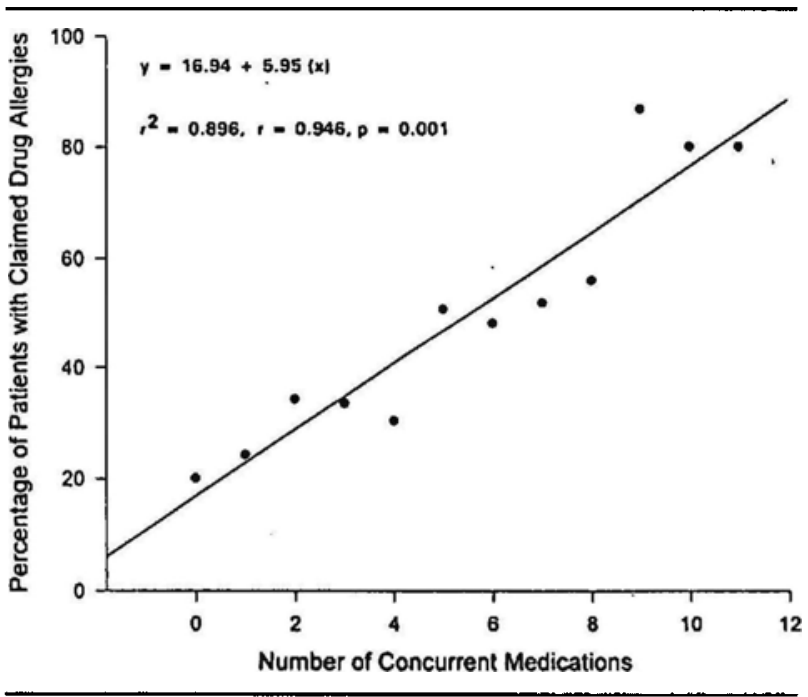

FIGURE 3 The relationship between the number of medications used by the patients and the percentage of patients with claimed drug allergies.

drugs were the second most common in the group (25\%) with $64 \%$ in the high probability group for allergic reactions. On the other hand, $83 \%$ of the claimed opioid allergies were associated with reactions that had a low probability of an allergic reaction (Figure 4). Codeine accounted for $45 \%$ of the opioid group with $79 \%$ of these reactions below low probability (Table III). Meperidine (23\%) and morphine (19\%) were the next most common opioids with $93 \%$ and $79 \%$, respectively, having a low probability of allergic reaction. Acetylsalicylic acid accounted for $68 \%$ of the reactions in the NSAID group of which $62 \%$ were low probability of allergic reaction (Table IV and Figure 4). All acetaminophen allergies were associated with low probability of allergic reactions. Most of the sedatives/hypnotics (67\%), including the benzodiazepines and antihistamines, were associated with low probability of allergic reactions (Table $\mathrm{V}$ and Figure 4).

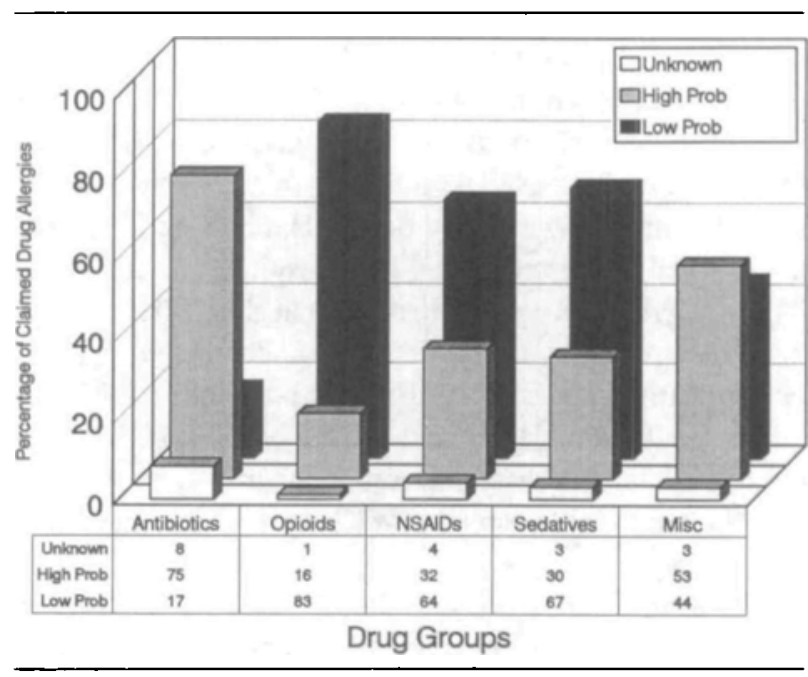

FIGURE 4 Validity of claimed drug allergies in different groups of drugs.

It was of interest that $100 \%$ of the 11 reactions due to IVP contrast had features of a high probability of allergic reaction.* Six patients reported reactions to local anaesthetics $(0.01 \%)$ and there was a $50 \%$ incidence of high probability of allergic reactions. There was one report of nausea and vomiting due to thiopentone and one patient had hallucinations following a general anaesthetic. One female patient who claimed to have an allergy to penicillin, had an anaphylactic or anaphylactoid reaction during a general anaesthetic shortly after induction. The drugs implicated were thiopentone, fentanyl and pancuronium.

\section{Discussion}

This study demonstrates that more than one quarter of surgical patients claim to have one or more drug allergies,

*A detailed list of drug allergies is available from Dr. Orlando Hung upon request. 
TABLE III Validity of claimed opioid allergies

\begin{tabular}{lccccl}
\hline Opioids & $\begin{array}{c}\text { High } \\
\text { prob }\end{array}$ & $\begin{array}{c}\text { Low } \\
\text { prob }\end{array}$ & Unknown & Total & $\begin{array}{l}\text { Percentage of total opioid } \\
\text { allergies }\end{array}$ \\
\hline Codeine & 16 & 63 & 1 & 80 & 44.9 \\
Meperidine & 2 & 38 & 1 & 41 & 23.0 \\
Morphine & 6 & 26 & 1 & 33 & 18.5 \\
Pentazocine & 3 & 13 & 0 & 16 & 9.0 \\
Others & $\frac{7}{14}$ & $\frac{7}{147}$ & $\underline{3}$ & $\frac{8}{178}$ & $\frac{4.5}{100}$ \\
Total & 28 & 147 & & \\
Percentage & 15.7 & 82.6 & 1.7 & 100 & \\
\hline
\end{tabular}

TABLE IV Validity of the claimed allergies to analgesics and anti-inflammatory drugs.

\begin{tabular}{lcclcl}
\hline Drugs & $\begin{array}{c}\text { High } \\
\text { prob }\end{array}$ & $\begin{array}{c}\text { Low } \\
\text { prab }\end{array}$ & Unknown & Total & $\begin{array}{l}\text { Percentage of total NSAID } \\
\text { allergies }\end{array}$ \\
\hline Acetylsalicylic acid & 14 & 28 & 3 & 45 & 68.1 \\
Acetaminophen & 0 & 9 & 0 & 9 & 13.6 \\
Others & $\frac{7}{21}$ & $\frac{5}{42}$ & $\frac{0}{3}$ & $\frac{10}{66}$ & $\frac{15.1}{100}$ \\
Total & 21 & & & 100 & \\
Percentage & 32 & 64 & 4 & &
\end{tabular}

TABLE V Validity of the claimed allergies to anxiolytics, sedatives, and antihistamines

\begin{tabular}{lccccc}
\hline Drugs & $\begin{array}{c}\text { High } \\
\text { prob }\end{array}$ & $\begin{array}{c}\text { Low } \\
\text { prob }\end{array}$ & Unknown & $\begin{array}{l}\text { Total } \\
\text { number }\end{array}$ & $\begin{array}{l}\text { Percentage of total allergies } \\
\text { of this group }\end{array}$ \\
\hline Benzodiazepines & 4 & 15 & 0 & 19 & 57.6 \\
Other sedatives & 2 & 5 & 0 & 7 & 21.2 \\
Antihistamines & $\underline{4}$ & $\underline{2}$ & $\underline{1}$ & $\frac{7}{33}$ & $\frac{21.2}{100}$ \\
Total & 10 & 22 & 1 & 100 & \\
Percentage & 30.3 & 66.7 & 3 & & \\
\hline
\end{tabular}

although only $50 \%$ of these claimed drug allergies have a high probability of being true allergic reactions. The remaining claimed drug allergies were most likely due to predictable adverse drug reactions. Similar mislabelling of drug allergies has been reported by Delafuente. ${ }^{6}$ Following chart reviews and interviewing 50 patients, Delafuente found that only $45 \%$ of stated drug allergies were valid. Antibiotics, opioids and NSAIDs accounted for $80 \%$ of these allergies which was similar to our observations.

Allergic drug reactions are defined as reactions mediated by either specific antibodies or lymphocytes. They fall into one of four classes of hypersensitivity described by Coombs and Gell. ${ }^{14}$ Type I (immediate hypersensitivity) reactions are mediated by the $\operatorname{IgE}$ antibody and are usually associated with the mast cells and basophils. Historically, true anaphylaxis is initiated by IgEdependent activation of these cells. However, non- immunological stimulation of release of mediators, such as histamine, from mast cells, may lead to clinically indistinguishable syndromes that are referred to as anaphylactoid or pseudoallergic reactions. Type II reactions are cytotoxic. These reactions are caused by an IgG or IgM antibody that is directed at a cell-surface antigen which activates the complement cascade leading to cell lysis. A type III reaction is caused by soluble, circulating complexes of antigen and IgG or IgM antibody. In the presence of complement, these complexes damage blood vessel walls and basement membranes. Type IV reactions involve specifically sensitized lymphocytes, rather than antibodies. Following sensitization by a drug or antigen, the lymphocytes react by releasing lymphokines which mediate an inflammatory response to antigen. Ideally, the diagnosis of an allergic reaction should be made by objective in vivo or in vitro testing which has been shown to be reliable in identifying allergies to specific drugs. 
Unfortunately, in the majority of cases, the actual drugs causing the allergic reactions are unknown. Therefore, the diagnosis of most drug allergies is presumptive and is based upon clinical signs and symptoms and their temporal relationship with the offending drugs. An accurate and comprehensive history remains the most important aspect in assessing allergy. Unfortunately, the allergic drug history from patients is often difficult to obtain and frequently misleading or incomplete. Reactions to drugs such as penicillin often occur during childhood. Memory of a rash following a course of penicillin was common. However, the nature of the rash or its temporal relationship to drug ingestion were frequently vague or unavailable. It was uncertain whether the reported rash was secondary to infectious disease, or the antibiotics involved. Similarly, rash following the administration of IVP contrast may have been an immunological event, or the result of histamine release (anaphylactoid reaction), both common with IVP contrast. This was also true with the symptom of itching following drug administration.

Apart from genetic factors, concurrent medications, and concurrent medical illnesses, clinical manifestations of drug allergy can also be influenced by the dose, duration and route of administration of the drug. ${ }^{15}$ For example, oral administration of penicillin is less likely to provoke a systemic reaction than parenteral administration of the drug. ${ }^{16-17}$ This may partially explain the higher frequency of allergic responses to anaesthetics since most of the anaesthetics are administered intravenously. However, during our preoperative assessment, we did not determine the route of administration of the claimed drug allergies. It was, therefore, not possible for us to examine the relationship between drug allergies and the route of drug administration.

One of our major difficulties was the assignment of claimed drug allergies to different probability groups. When in doubt, we placed the reaction in the high probability group to err on the safe side. Therefore, there may be fewer true allergic reactions than we reported. It should also be emphasized that it was not the intention of this study to determine the reliability of the patients' recall of symptoms and signs of the adverse drug reactions, or the correct diagnosis of a true drug allergy. Rather, it was designed to determine the magnitude of the general misconception or misinterpretation of predictable side effects of drugs as allergic drug reactions.

Some of the claimed drug allergies, such as to tylenol \#3 or Frosst 292, consist of more than one ingredient. So the total number of claimed allergies to these drugs, such as acetaminophen, acetylsalicylic acids, and codeine in this study was potentially overestimated. However, the overall number of patients who claimed to have drug allergies should remain unchanged.
Even though there was no sex difference in the number of drugs taken, women had more claimed drug allergies than men. This was consistent with the findings from other studies. ${ }^{13,14}$ The incidence of high probability reactions between women and men was comparable $(48 \%$ and 52\%). There are no clear explanations for this observation. Perhaps women tend to remember adverse drug reactions better than men, or feel more comfortable in reporting them.

The relationship between age, number of medications and claimed allergies was expected. The frequency of disease increases with age as do the taking of medications and their adverse drug reactions. The greater the exposure to drugs, the more likely an adverse drug reaction will occur. Our data have demonstrated that there is a high probability ( $>90 \%$ chance) that a patient who is taking more than ten medications will report one or more drug allergies.

There is some evidence to suggest that patients who have experienced an allergic reaction to one drug may react to one or many other drugs. ${ }^{17}$ The reasons for this phenomenon are unclear but it may be a reflection of cross-sensitivity. It is also possible that when two drugs are administered simultaneously or in close temporal relationship and both produce allergic reactions, the initial drug reaction may have predisposed to the second by decreasing the threshold of allergic reactivity. ${ }^{17}$ It has been suggested that a history of atopy or allergy is a predisposing factor to allergic reaction to an intravenous anaesthetic such as thiopentone. ${ }^{18}$ However, in this study, only one patient with a history of penicillin allergy had a reaction to the anaesthetic drugs. Therefore, it is not possible to predict the risk of a patient developing an allergic reaction to anaesthetic drugs on the basis of an alleged allergic drug reaction.

Following the report of our preliminary results, a review was conducted by the Quality Assurance and Risk Management Department at the Victoria General Hospital to determine the adequacy of allergy documentation. In a three-month period, 1789 out of 5606 patients (32\%) discharged from the hospital were identified with at least one drug allergy. More patients in the medical services (35.0\%) claimed to have one or more drug allergies than those in the surgical population (29.1\%). A random chart review was carried out in 165 patients with a history of drug allergy and 279 drug allergies were identified. The study found that there were no standards regarding the reporting of allergies or adverse drug reactions by medical staff. Only $75.1 \%$ of the drug allergies were recorded by the medical staff (residents, interns and clinical clerks) in the history and physical examination of the patients' chart and only $22.6 \%$ reported the nature of the allergic reactions. It was also surprising that only 
74 out of $279(26.5 \%)$ drug allergies were recorded in the discharge summary. Similarly, only 100 out of 133 allergies $(75.2 \%)$ were recorded on the anaesthetic record and only $24.8 \%$ recorded the nature of the drug reactions. Of special interest, 27 (16.4\%) patients received drugs to which the patients claimed to be allergic. Fortunately, there was no evidence or documentation of any problems or reactions following the administration of the drugs in question. This review indicated that appropriate allergy documentation by the medical staff, including the nature of the drug reacction, was inadequate. Similar poor allergy documentation has been reported by other institutions. ${ }^{11-13}$ Approximately $20-30 \%$ of the health care personnel did not document history of drug allergies in patients' admission notes.

Based on the findings of our study, the following recommendations are made: (1) health care personnel, especially physicians, should take an active role in determining the validity of claimed drug allergies in their patients by taking a thorough history to assess their medical status; (2) complete documentation of the symptoms and signs of all reported allergies must be present on patients charts; (3) to avoid confusion with drug intolerance, a revision of hospital policies and guidelines for the diagnosis of drug allergies is necessary; (4) a distinctive alert system using a colour-coded bracelet for drug allergies and drug intolerance should be employed to alert health care providers; (5) proper education should be provided to health care providers and patients regarding the diagnosis of drug allergies and drug intolerance; (6) involvement of other health care personnel, such as pharmacists, may be extremely useful in the detection and documentation of drug allergies, as well as in the development of policies and guidelines for a drug allergy alert system in the hospital.

In summary, this study has shown that more than one quarter of the surgical patients interviewed (28.1\%) claimed to have one or more drug allergies. The majority of allergies to antibiotics $(75 \%)$ were associated with a high probability of true drug allergies. However, the majority $(76.2 \%)$ of the remaining drug allergies (including opioids, nonsteroidal anti-inflammatory agents, and sedatives/hypnotics) were associated with a low probability of true allergic reactions. Overall, only $50 \%$ of the reported drug allergies have clinical histories which are compatible with true allergic reactions. Our findings, which are similar to those found in other hospitals, suggest a serious problem in the "labelling," as well as documentation, of drug allergies in our patients. Unnecessary "mislabelling," which has considerable legal implications and a potential for adding costs to the health care system by using an expensive alternative drug, can be minimized by proper education of patients and health care personnel.

\section{References}

1 Levenson DE, Arndt KA, Stern RS. Cutaneous manifestations of adverse drug reactions. Immunology and Allergy Clinics of North America 1991; 11: 493-507.

2 Jick $H$. Adverse drug reations: the magnitude of the problem. J Allergy Clin Immunol 1984; 74: 555-7.

3 DeSwarte RD. Drug allergy - problems and strategies. J Allergy Clin Immunol 1984; 74: 209-24.

4 Wedner $H J$. Drug allergy prevention and treatment. Immunology and Allergy Clinics of North America 1991; 11 : 679-94.

5 Kuehm SL, Doyle MJ. Medication errors: 1977 to 1988. Experience in medical malpractice claims. N J Med 1990; 87: 27-34.

6 Delafuente JC. Is it really a drug allergy? Hospital Formulary 1985; 20: 355-9.

7 Hardin TC, Mubarek H, Melikian DM. Profile of stated drug allergies in hospitalized patients (Letter). Am J Hosp Pharm 1981; 38: 1879.

8 Cradock JC, Whitfield GR, Menzie JW, Fortner CL. Postadmission drug and allergy histories recorded by a pharmacist. Am J Hosp Pharm 1972; 29: 250-2.

9 Swallow RD, Swan AJ. Drug sensitivities in hospital patients. Pharmaceutical Journal 1986; 236: 228-9.

10 Glover $R$, Trottier $L$. Pharmacy involvement in the evaluation of drug allergies. Canadian Journal of Hospital Pharmacy' 1977; 30: 38-44.

11 Basger BJ, Eckert GM. The role of the clinical pharmacist in the detection, investigation and the prevention of allergic drug reactions. Australian Journal of Hospital Pharmacy 1982; 12: 45-8.

12 Pau AK, Morgan JE, Terlingo A. Drug allergy documentation by physicians, nurses, and medical students. Am J Hosp Pharm 1989; 46: 570-3.

13 Geibig CB, Mansur JM, Medema PG, Nold EG. Pharmacy-controlled documentation of drug allergies. Am J Hosp Pharm 1991; 48: 260-4.

14 VanArsdel PP Jr. Diagnosing drug allergy. JAMA 1982; 247: 2576-81.

15 Sullivan TJ. Drug allergy. In: Middleton E, Reed CE, Ellis EF, Adkinson NF, Yunginger JW (Eds.). Allergy: Principles and Practice, 3rd ed. St. Louis: C.V. Mosby Co., 1988; 1523-36.

16 Herman $R$, Jick $H$. Cutaneous reaction rates to penicillins: oral versus parenteral. Cutis 1979; 24: 232-4.

17 Parker CW. Drug allergy (second of three parts) N Engl J Med 1975; 292: 732-6.

18 Clarke RSJ. Adverse effects of intravenously administered drugs used in anaesthetic practice. Drugs 1981; 22: 26-41. 